\title{
Potentiated Adherence of Sickle Erythrocytes to Endothelium Infected by Virus
}

\author{
Robert P. Hebbel, Maarten R. Visser, Jesse L. Goodman, Harry S. Jacob, and Gregory M. Vercellotti
}

Department of Medicine, University of Minnesota Medical School, Minneapolis, Minnesota 55455

\begin{abstract}
Systemic viral infection is a known precipitant of vasocclusive crisis in sickle patients, but the mechanism underlying this clinical observation is unknown. In the present studies, human umbilical vein endothelial cells were infected with Herpes simplex virus type 1 (HSV) to model systemic viral disease. The already abnormal adherence of sickle erythrocytes to control endothelium is enhanced $1.8 \pm 0.4$-fold to $\mathrm{HSV}$-infected endothelium $(P<0.001)$. This component of potentiated adherence is eliminated by maneuvers that block Fc receptors, it is prevented by tunicamycin, and it is not seen using a mutant HSV that is unable to express the Fc receptor glycoprotein. Thus, the incremental adherence seen here occurs due to expression of Fc receptor activity on HSV-infected endothelium and the consequent recognition of abnormal amounts of IgG on sickle erythrocytes. We conclude that systemic viral infection potentially can induce a novel mechanism for enhancement of erythrocyte adherence to endothelium and that this may increase the likelihood of vasocclusion during viral infection.
\end{abstract}

\section{Introduction}

The clinical course of sickle disease is remarkable for its episodic punctuation with microvascular occlusive events leading to painful crises $(1,2)$. Although the precise pathophysiology of vasocclusion is still understood only incompletely, several investigations have addressed the possibility that abnormal interactions between sickle erythrocytes $(\mathrm{RBC})^{1}$ and endothelium might underlie clinical vasocclusion (3-9). Sickle $R B C$ are abnormally adherent to human vascular endothelial cells (4-9), and the degree of adherence correlates with overall clinical vasocclusive severity $(5,6)$, although causality is not yet established. Of interest, clinical observation has implicated a number of factors as being precipitants of these vasocclusive crises $(1,2)$. In some cases, such associations are easily understood. For example, hypoxia would promote erythrocyte sickling and, therefore, cause microvascular obstruction. In con-

Address correspondence to Dr. Hebbel, Box 480 UMHC, University of Minnesota Hospital, Harvard St. at East River Rd., Minneapolis, MN 55455.

Received for publication 18 February 1987 and in revised form 30 July 1987.

1. Abbreviations used in this paper: HSV, Herpes simplex virus type 1; RBC, erythrocyte.

J. Clin. Invest.

(C) The American Society for Clinical Investigation, Inc.

$0021-9738 / 87 / 11 / 1503 / 04 \$ 2.00$

Volume 80, November 1987, 1503-1506 trast, the mechanism underlying the association between systemic viral infection and vasocclusive crisis remains obscure. The present studies were undertaken to examine the hypothesis that systemic viral infection might predispose toward vasocclusion by enhancing interactions between sickle RBC and altered endothelium.

\section{Methods}

Endothelial cells were obtained from human umbilical veins and grown in primary culture in 24-well culture plates, as previously described $(4,5)$. After confluence was attained, some endothelial cells were left intact (controls), while some were inoculated with Herpes simplex virus type 1 (HSV). For most of these studies, we used HSV strain 17 syn $+(10)$ and a multiplicity of infection of 10 plaque-forming units per cell. After incubation for $18 \mathrm{~h}$ at $37^{\circ} \mathrm{C}$, the cells revealed early cytopathic changes by light microscopy and contained typical intranuclear viral particles by electron microscopy. However, endothelium remained attached to the plastic culture wells as a confluent monolayer and continued to exclude trypan blue. The adherence of normal and sickle $\mathrm{RBC}$ to endothelium was determined as previously described $(4,5)$ using suspensions of washed, ${ }^{51} \mathrm{Cr}$-labeled $\mathrm{RBC}$ at hematocrit $25 \%$ in Hanks' balanced salt solution (HBSS) containing $0.5 \%$ albumin. For some experiments, endothelium was preincubated for $30 \mathrm{~min}$ with HBSS containing $5 \mathrm{mg} / \mathrm{ml}$ aggregated human IgG (obtained from serum using Staphylococcal protein A [11]) or HBSS containing $2 \mathrm{mg} / \mathrm{ml}$ of its $\mathrm{Fc}$ or $\mathrm{F}\left(\mathrm{ab}^{\prime}\right)_{2}$ fragments (obtained from Cooper Biomedical Inc., Malvern, PA). The adherence assay was then performed using these same concentrations of IgG or fragments in the buffer used for RBC suspension and endothelial washing. For other experiments, we co-incubated endothelium with tunicamycin ( 3 $\mu \mathrm{g} / \mathrm{ml}$ ) at the time of inoculation with HSV. A final set of experiments used viral strains kindly provided to Dr. Goodman by Dr. H. Neidhart (German Cancer Research Center, Heidelberg, FRG): the HSV-1 Angelotti parent strain and a derived mutant strain, which is unable to express glycoprotein gE (12).

\section{Results}

The result of a typical experiment is depicted in Fig. $1 A$, which illustrates the removal of sickle and normal RBC from control and infected endothelium. As reflected in the rates of $R B C$ removal by sequential endothelial washing, the adherence of normal RBC to control and to infected endothelial cells is similar. In contrast, the adherence of sickle RBC is enhanced by infection of the endothelium with HSV (Fig. $1 A$ ). Results of this comparison of $\mathrm{RBC}$ from six normal and six sickle donors (Fig. 2) show that the already abnormal adherence of sickle RBC to control endothelium is increased $1.8 \pm 0.4$-fold to HSV-infected endothelium $(P<0.001)$.

HSV is known to induce expression on infected cells of a glycoprotein (gE) which is a receptor for the Fc portion of IgG $(13,14)$. In the present studies, the absence of Fc receptor 

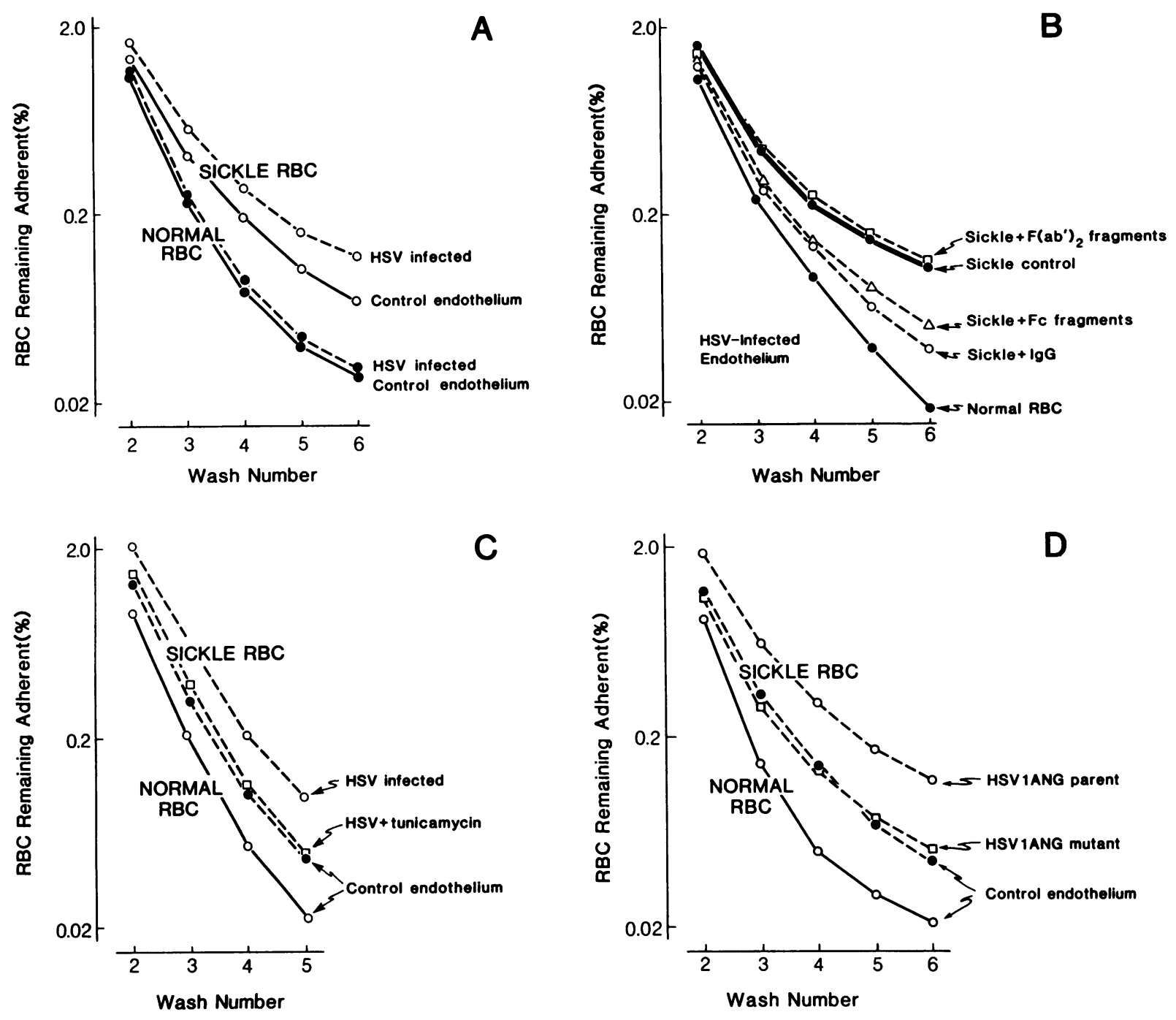

Figure 1. Representative experiments comparing adherence of sickle and normal RBC to uninfected (control) and HSV-infected human umbilical vein endothelial cells. Chromium-labeled RBC suspended in HBSS were layered on washed confluent monolayers of endothelial cells in primary culture. Tendency of $R B C$ to adhere to endothelium is evident in the rate of their removal by sequential endothelial washing. Each panel depicts percentage of $\mathrm{RBC}$ remaining adherent as a function of endothelial wash number. $(A)$ Normal (๑) and sickle (O) RBC examined on HSV-infected (---) and control (-) endothelium. (B) Normal RBC and sickle RBC on HSV-infected endothelium (bottom curve and curve labeled sickle control, respectively). Broken curves show effect on adherence of $5 \mathrm{mg} / \mathrm{ml}$ aggregated

activity on control endothelium and the appearance of $\mathrm{gE}$ on HSV-infected endothelium (13) was documented by showing that sheep RBC opsonized with IgG (but not those opsonized with IgM) formed rosettes with HSV-infected endothelium but not with control endothelium (data not shown). Therefore, we considered the possibility that the component of potentiated adherence of sickle RBC to HSV-infected endothelium might be mediated by the abnormal amounts of IgG on sickle RBC $(11,15-17)$.

Preincubation of endothelium with aggregated human IgG $(5 \mathrm{mg} / \mathrm{ml})$ had no effect whatsoever on adherence of either normal or sickle RBC to control endothelium, nor did it affect

human $\operatorname{IgG}(0)$ or its $\mathrm{Fc}(\Delta)$ or $\mathrm{F}\left(\mathrm{ab}^{\prime}\right)_{2}$ (口) fragments at $2 \mathrm{mg} / \mathrm{ml}$. (C) Normal and sickle RBC on uninfected, control endothelium are shown by bottom two curves. Top curve shows sickle RBC on HSVinfected endothelium. HSV + tunicamycin curve shows effect of preventing viral glycoprotein expression by adding the glycosylation inhibitor tunicamycin $(3 \mu \mathrm{g} / \mathrm{ml})$ at the time of inoculation with virus. (D) Normal and sickle RBC on control endothelium are shown by the bottom two curves. Top two curves show sickle RBC on endothelium infected with the HSV-1 Angelotti (HSVIANG) parent strain and on endothelium infected with the derived mutant lacking ability to express glycoprotein $\mathrm{gE}$ and $\mathrm{Fc}$ receptor activity.

interaction of normal RBC with HSV-infected endothelium (data not shown). However, the presence of aggregated IgG diminished the adherence of sickle RBC to HSV-infected endothelium by $46.5 \pm 10.3 \%(P<0.01)$. This reduction is of precisely the magnitude required to eliminate the mean 1.8 fold potentiation of adherence to HSV-infected endothelium. The representative experiment shown in Fig. $1 B$ demonstrates this inhibitory effect of $\mathrm{IgG}$ and illustrates that $\mathrm{Fc}$ fragments of IgG are almost as effective, while $F\left(a b^{\prime}\right)_{2}$ fragments have no inhibitory effect. For the specific case illustrated in Fig. $1 B$, the inhibitory effect of IgG reduced sickle RBC adherence from 3.1 times normal to 2.0 times normal; the latter figure is ex- 


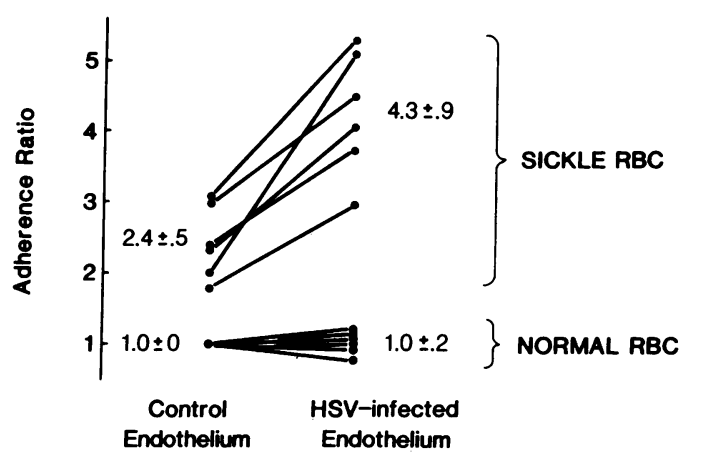

Figure 2. Summarized results of endothelial adherence studies on all six sickle cell anemia patients. For each study, RBC from a different pair of normal and sickle patients were compared for adherence to control and HSV-infected endothelial cells. This was measured as described for Fig. $1 A$, but results are here expressed as the "adherence ratio" to simplify data presentation (4-6). The adherence ratio is equal to the percentage of test cells (normal RBC on infected endothelium, or sickle RBC on either infected or control endothelium) remaining adherent after the last endothelial wash, divided by the percentage of normal cells remaining adherent to control endothelium. Thus, results are expressed relative to the adherence of normal RBC to control endothelium, which is defined as having an adherence ratio of 1.0 .

actly the magnitude of that patient's baseline RBC adherence to control endothelium.

Since the present studies were done in the prelytic phase of viral infection, our results should not reflect damage to the endothelial cell membrane with consequent exposure of intracellular substances (e.g., vimentin) having Fc receptor activity (18). To be certain of this, we co-incubated endothelium with tunicamycin $(3 \mu \mathrm{g} / \mathrm{ml})$ at the time of inoculation with HSV. This specific glycosylation inhibitor is known to inhibit expression of viral glycoproteins on HSV-infected cells, and treatment with glycosylation inhibitors inhibits induction of Fc receptor expression by HSV (19-22). In parallel with the failure of Fc receptor activity to appear on infected cells (as shown by rosetting studies using sheep RBC opsonized with $\mathrm{IgG}$ ), endothelium infected in the presence of tunicamycin lost its ability to potentiate sickle RBC adherence (Fig. $1 C$ ). However, the residual component of adherence persisting despite tunicamycin was precisely the magnitude of that for sickle adherence to control endothelium, indicating that the basal abnormality of endothelial adherence was preserved.

Three additional control experiments addressed the relevance and/or mechanism of these results. First, the described potentiation of sickle adherence was just as evident if these experiments were performed in citrated plasma, and the result was the same whether or not the plasma had been depleted of IgG (data not shown). Thus, as expected, presence of normal monomeric IgG did not block the phenomenon. Second, normal $R B C$ having $D$ antigen did show potentiated adherence to HSV-infected endothelium if they were made Coombs positive by preincubation with an IgG having anti-D activity (data not shown). Finally, we found that sickle RBC failed to show potentiated adherence to endothelium infected with a mutant HSV that was unable to express the viral glycoprotein (gE) having Fc receptor activity (12). Fig. $1 D$ compares this deficient mutant with its parent strain, where both are used at a multiplicity of infection of 10 . This difference in expression of
Fc receptor activity is also seen using the mutant strain at a multiplicity of infection that is tenfold higher than that used for the parent strain (data not shown), so results are not simply explained by the fact that this mutant replicates to a slightly lower titer than the parent strain (12).

\section{Discussion}

The present data document that the already abnormal adherence of sickle $\mathrm{RBC}$ to vascular endothelium is enhanced almost twofold to endothelium infected with Herpes simplex virus type 1 . This specific virus is merely one of many known to infect human endothelium in vitro: Herpes simplex type 1, adenovirus, measles, mumps, parainfluenza, poliovirus, echovirus, and cytomegalovirus $(23,24)$. In addition, a number of viruses have been shown thus far to induce Fc receptors on the membranes of infected cells: Herpes simplex types 1 and 2, cytomegalovirus, Varicella zoster, and influenza (13, 14, 25-27). In the case of Herpes simplex type 1 , the virus induces appearance of a number of glycoproteins, one of which $(\mathrm{gE})$ is a functional Fc receptor (28).

Our results indicate that expression of this Fc receptor activity on infected cells allows endothelium to "recognize" the abnormal amounts of $\operatorname{IgG}$ on sickle $\operatorname{RBC}(11,15-17)$. This IgG is a partial explanation for the abnormal adherence of sickle RBC to human macrophages (11), but it is not involved in adherence of sickle RBC to control endothelium $(4,11)$. In fact, an examination of RBC from 14 sickle patients failed to identify any correlation between RBC adherence to (control) endothelium and RBC adherence to macrophages (11), suggesting that different mechanisms underlie the two phenomena. Thus, only the component of potentiated adherence to HSV-infected endothelium is mediated by this IgG.

Hence, the sickle patient infected with an appropriate virus might acquire, during the period of active infection, a new mechanism predisposing toward enhanced risk of vasocclusive phenomena. Furthermore, this might even be relevant to the peculiar development of regional vasocclusive phenomena in sickle patients. For example, the sudden development of catastrophic pulmonary vasocclusive crisis (1) could perhaps be explained by viral infection involving the endothelium of the pulmonary circulation. While such infection of pulmonary endothelium has not yet been specifically reported, viral infection of other endothelia in vivo in human disease has been documented (29). Although necessary comparable studies on human tissue have not yet been performed, study of bovine endothelium in vitro suggests that endothelial cells derived from different sources (i.e., thoracic aorta, pulmonary vein, umbilical vein) are equally susceptible to infection with virus (30). Thus, it is reasonable to assume that these studies of umbilical vein endothelial cells are relevant to endothelium of various organs. Consequently, these results may help explain the well-established clinical association between systemic viral infection and vasocclusive crisis in patients with sickle disease.

\section{Acknowledgments}

We thank Dr. J. G. White for performing electron microscopic studies and Dr. H. Neidhardt for providing J. L. Goodman with the glycoprotein $\mathrm{gE}$ deletion mutant HSV.

This work was supported by National Institutes of Health (grants HL-01130, HL-30160, AM-34931, AM-01387, and HL-33793) and the Minnesota Medical Foundation. 


\section{References}

1. Bunn, H. F., and B. G. Forget. 1986. Sickle cell disease: clinical and epidemiological aspects. In Hemoglobin: Molecular, Genetic and Clinical Aspects. W.B. Saunders Co., Philadelphia. 502-564.

2. Diggs, L. W. 1965. Sickle cell crisis. Am. J. Clin. Pathol. 44:1-19.

3. Hoover, R., R. Rubin, G. Wise, and R. Warren. 1979. Adhesion of normal and sickle erythrocytes to endothelial monolayer cultures. Blood. 54:872-876.

4. Hebbel, R. P., O. Yamada, C. F. Moldow, H. S. Jacob, J. G. White, and J. W. Eaton. 1980. Abnormal adherence of sickle erythrocytes to cultured vascular endothelium: possible mechanism for microvascular occlusion in sickle cell disease. J. Clin. Invest. 65:154-160.

5. Hebbel, R. P., M. A. B. Boogaerts, J. W. Eaton, and M. H. Steinberg. 1980. Erythrocyte adherence to endothelium in sickle-cell anemia: a possible determinant of disease severity. N. Engl. J. Med. 302:992-995.

6. Hebbel, R. P., C. F. Moldow, and M. H. Steinberg. 1981. Modulation of erythrocyte-endothelial interactions and the vasocclusive severity of sickling disorders. Blood. 58:947-952.

7. Kucukcelebi, A., S. P. Barmatoski, and M. I. Barnhart. 1980. Interactions between vessel wall and perfused sickled erythrocytes. Scanning Electron Microsc. 3:243-248.

8. Mohandas, N., and E. Evans. 1984. Adherence of sickle erythrocytes to vascular endothelial cells: requirement for both cell membrane changes and plasma factors. Blood. 64:282-287.

9. Burns, E. R., W. H. Wilkinson, and R. L. Nagel. 1985. Adherence properties of sickle erythrocytes in dynamic flow systems. J. Lab. Clin. Med. 105:673-678.

10. Subak-Sharpe, J. H., S. M. Brown, D. A. Ritchie, M. C. Timbury, J. C. M. Macnab, H. S. Marsden, and J. Hay. 1974. Genetic and biochemical studies with Herpesvirus. Cold Spring Harbor Symp. Quant. Biol. 39:717-730.

11. Hebbel, R. P., and W. J. Miller. 1984. Phagocytosis of sickle erythroctes: immunologic and oxidative determinants of hemolytic anemia. Blood. 64:733-741.

12. Neidhardt, H., C. H. Schröder, and H. C. Kaerner. 1987. Herpes simplex virus type 1 glycoprotein $\mathrm{E}$ is not indispensable for viral infectivity. J. Virol. 61:600-603.

13. Cines, D. B., A. P. Lyss, and M. Bina. 1982. Fc and C3 receptors induced by Herpes simplex virus on cultured human endothelial cells. J. Clin. Invest. 69:123-128.

14. Para, M. F., L. Goldstein, and P. G. Spear. 1982. Similarities and differences in the Fc-binding glycoprotein (gE) of Herpes simplex virus types 1 and 2 and tentative mapping of the viral gene for this glycoprotein. J. Virol. 41:137-144.

15. Petz, L. D., P. Yam, L. Wilkinson, G. Garratty, B. Lubin, and W. Mentzer. 1984. Increased IgG molecules bound to the surface of red blood cells of patients with sickle cell anemia. Blood. 64:301-304.
16. Green, G. A., M. M. Rehn, and V. K. Kalra. 1985. Cell-bound autologous immunoglobulin in erythrocyte subpopulations from patients with sickle cell disease. Blood. 65:1127-1133.

17. Galili, U., M. R. Clark, and S. B. Shohet. 1986. Excessive binding of natural anti-alpha-galactosyl immunoglobin $\mathrm{G}$ to sickle erythrocytes may contribute to extravascular cell destruction. J. Clin. Invest. 77:27-33.

18. Hansson, G. K., G. A. Starkebaum, E. P. Benditt, and S. M. Schwartz. 1984. Fc-mediated binding of IgG to vimentin-type intermediate filaments in vascular endothelial cells. Proc. Natl. Acad. Sci. USA. 81:3103-3107.

19. Pizer, L. I., G. H. Cohen, and R. J. Eisenberg. 1980. Effect of tunicamycin on Herpes simplex virus glycoproteins and infectious virus production. J. Virol. 34:142-153.

20. Norrild, B., and B. Pedersen. 1982. Effect of tunicamycin on the synthesis of Herpes simplex virus type 1 glycoproteins and their expression on the cell surface. J. Virol. 43:395-402.

21. Costa, J., C. Yee, Y. Nakamura, and A. Rabson. 1978. Characteristics of the Fc receptor induced by Herpes simplex virus. Intervirology. 10:32-39.

22. McTaggart, S. P., W. H. Burns, D. O. White, and D. C. Jackson. 1978. Fc receptors induced by Herpes simplex virus. I. Biologic and biochemical properties. J. Immunol. 121:726-730.

23. Friedman, H. M., E. J. Macarak, R. R. MacGregor, J. Wolfe, and N. A. Kefalides. 1981. Virus infection of endothelial cells. J. Infect. Dis. 143:266-273.

24. Ho, D. D., T. R. Rota, C. A. Andrews, and M. S. Hirsh. 1984. Replication of human cytomegalovirus in endothelial cells. J. Infect. Dis. 150:956-957.

25. Ryan, U. S., D. R. Schultz, and J. W. Ryan. 1981. Fc and C3b receptors on pulmonary endothelial cells: induction by injury. Science (Wash. DC). 214:557-558.

26. Keller, R., R. Peitchel, J. N. Goldman, and M. Goldman. 1976. An IgG-Fc receptor induced in cytomegalovirus-infected human fibroblasts. J. Immunol. 116:772-777.

27. Ogata, M., and S. Shigeta. 1979. Appearance of immunoglobulin $\mathrm{G}$ Fc receptor in cultured human cells infected with Varicella zoster virus. Infect. Immun. 26:770-774.

28. Para, M. F., R. B. Baucke, and P. G. Spear. 1982. Glycoprotein $\mathrm{gE}$ of Herpes simplex virus type 1: effects of anti-gE on virion infectivity and on virus-induced Fc-binding receptors. J. Virol. 41:129-136.

29. Friedman, H. M. 1984. Viral infection of endothelium and the induction of Fc and C3 receptors. In Biology of Endothelial Cells. E. A. Jaffe, editor. Martinus Nijhoff, Boston. 268-276.

30. Friedman, H. M., J. Wolfe, N. A. Kefalides, and E. J. Macarak. 1986. Susceptibility of endothelial cells derived from different blood vessels to common viruses. In Vitro Cell. Devel. Biol. 22:397-401. 